\title{
The Incentive Effects of Tournaments: The PGA Australasian Tour 1991
}

\author{
Erkin I. Bairam and John M. Howells*
}

This paper examines the relationship between the structure of tournament incentives and individual performance. Although it follows recent research on Professional Golf Association tournaments in the United States and Europe, it concentrates on the PGA Australasian Tour in 1991 for which financial incentives on average are much less attractive than for tournaments in the northern hemisphere. The results strongly confirm that tournaments do have an incentive effect. The incentive effects that such tournamenttype reward structures are clearly shown to have may be applicable not only to professional sport but also to industrial wage structures. Tournament models can offer a different perspective on the extent to which pay influences performance at the firm level.

\section{Introduction}

Essentially, efficiency-wage models are based on the proposition that the structure of compensation affects the productivity of workers. The presumption is that employee work effort, or efficiency, is a positive function of the wage rate: the higher the wage the firm pays, the harder its employees work. Although there are a number of different microeconomic foundations for these models (Akerlof, 1984; Yellen, 1984; Akerlof and Yellen, 1986; Stiglitz, 1987), the underlying assumption is the existence of a positive wageproductivity nexus. Since sporting competitions offer a reliable pool of data to test certain economic hypotheses (in contrast to the paucity of accurate measures both of employee effort and company incentive structures), it is not surprising that interest in the relationship between compensation structures and performance has encouraged research in tournament models (Lazear and Rosen, 1981; Carmichael, 1983; Green and Stokey, 1983; Malcomson, 1984; Nalebuff and Stiglitz, 1984; O'Keefe, Viscusi and Zeckhauser, 1984; Rosen, 1986; McLaughlin, 1988). Intuitively, given both the level and distribution of prize money, one might expect tournament rewards to offer individuals an incentive to provide improved levels of performance.

To test whether tournaments do in fact encourage appropriate effort responses, recent research by Ehrenberg and Bognanno (1990 a and b) has focused on Professional Golf Association (PGA) tournaments in the United States in 1984 and Europe in 1987. This

The authors wish to thank the University of Otago for financial support, Mark Allan for computational assistance, and Winston Cooper for providing data from official PGA publications not available to the researchers. The full data used in this study can be obtained from the authors on request. 


\section{Bairam and Howells}

provides an extremely useful testing procedure in a non-experimental setting using detailed information on actual incentive structures and also specific and accurate measures of individual performance. The present study extends this research to cover the 1991 PGA Australasian Tour where it is worth noting that financial incentives, on average, are appreciably less than the two PGA circuits in the northern hemisphere. ${ }^{1}$

\section{The 1991 PGA Australasian Tour}

This study covers the 13 tournaments in the 1991 Australasian Tour listed in Table I. Following Ehrenberg and Bognanno, it concentrates on "open" as opposed to match-play (or sudden-death) competitions. Each tournament is over four rounds, but only the leading 60 players are eligible to take part in the final two rounds. In "open" competitions, therefore, the individual plays against the rest of the competitors over a four-day period. Since the lowest score over 72 holes wins, performance is measured by the ability of players to score less than other competitors in the field.

TABLE 1

Australian Tournaments and Prize Money, 1991

\begin{tabular}{llll}
\hline Tournament & Prize Money & Tournament & Prize Money \\
\hline & $(\mathrm{A} \$)$ & & $(\mathrm{A} \$)$ \\
Johnnie Walker Classic & $1,000,000$ & Malaysian Masters & 291,000 \\
Australian Open & 700,000 & NZ Open & 189,875 \\
Australian PGA & 250,000 & Australian Masters & 500,000 \\
South Australian Open & 200,000 & Vines Classic & 700,000 \\
NZ Shell Open & 181,300 & Sanctuary Cove Classic & 700,000 \\
Singapore PGA & 150,000 & Palm Meadows Cup & $1,200,000$ \\
Perak Masters & 150,000 & & \\
\hline
\end{tabular}

Source: see the Official PGA Tour Guide 1991.

1 In United States and European tournaments included in the Ehrenberg-Bognanno surveys (using appropriate exchange rates to convert to Australian dollars), not one offered prize money less than A\$200,000; over 38 percent of Australasian toumaments were below this total. Again, prize money exceeded A\$500,000 in 77 percent of United States tournaments but only in 38 percent of Australasian tournaments. For Australasian data, see Table I and the Official PGA Tour Guide 1991. 
The level of prize money varied considerably across tournaments. However, the procedure for allocating total prize money, based on the rank order of the final 60 players at the end of each tournament, did not change during the Tour. The essential aspects of this procedure, illustrated in Table II, are similar to the structure for distributing prize money in the United States and European Tours surveyed in previous research. Australasian tournaments, therefore, also exhibit the critical feature of the structure of financial rewards, namely, that there is a much higher marginal return for improving performance in the final round by one rank to those close to the tournament leader than to those close to the bottom. In the Palm Meadows Cup, for example, the marginal return for coming first rather than second was $A \$ 86,000$ and for coming second rather than third was $A \$ 46,800$. Compare this with the difference of $\mathrm{A} \$ 240$ for coming fifty-ninth rather than last. Given information on total prize money and the fixed allocation procedure, it is possible to examine the relationship between performance and both the level of prize money and marginal returns to effort in the final round.

TABLE II

Distribution of Prize Money by Selected Ranks

\begin{tabular}{lllllllll}
\hline Rank & 1 & 2 & 3 & 4 & 5 & 6 & 7 & \\
$\begin{array}{l}\text { Prize Money } \\
(\%)\end{array}$ & 18.0 & 10.8 & 6.9 & 4.98 & 4.16 & 3.82 & 3.42 & \\
\hline & 8 & 9 & 10 & 20 & 30 & 40 & 50 & 60 \\
\hline $\begin{array}{l}\text { Rank } \\
\begin{array}{c}\text { Prize Money } \\
(\%)\end{array}\end{array}$ & 2.98 & 2.7 & 2.36 & 1.1 & 0.7 & 0.5 & 0.3 & 0.1 \\
\hline
\end{tabular}

Source: see the Official PGA Tour Guide 1991

All golf tournaments operate a complex system of exemptions relating to eligibility. For Australasian Tours, automatic entry (or exemption) is granted to the leading 60 players from the previous year's Tour, the leading five or ten players from other international tours in the previous year, winners of major tournaments in Australia or New Zealand, and Australian and New Zealand winners of major overseas tournaments. Those not granted exemption must qualify by their performance in a pre-qualifying round held prior to a specific tournament. Given that tournaments will include exempt and non-exempt players, it is possible that the relationship between financial incentive and performance will be different for the two groups. ${ }^{2}$ To allow for this, the model is estimated for both groups.

2 One view is that 'better players are, in fact, more responsive to financial incentives' (Ehrenberg and Bognanno, 1990a: 1322). On the other hand, many of the better exempt players on the Australasian Tour are successful in northern hemisphere toumaments where financial rewards are much greater. It might be assumed, therefore, that the incentive to improve performance on the less lucrative 


\section{The model: specification and estimation}

The model to be estimated (justified below) is specified as:

$$
\mathrm{FS}_{\mathrm{ij}}=f\left(\mathrm{EX}_{\mathrm{i}}, \mathrm{AO}_{\mathrm{j}}, \mathrm{RQ}_{\mathrm{ij}}, \mathrm{NT}_{\mathrm{j}}, \mathrm{PC}_{\mathrm{j}}, \mathrm{CL}_{\mathrm{j}}, \mathrm{PZ}_{\mathrm{j}}\right)+\varepsilon_{\mathrm{ij}}
$$

where

$\mathrm{FS}_{i j} \quad=$ final score (after four rounds) by individual $\mathrm{i}$ in tournament $\mathrm{j}$

$\mathrm{EX}_{\mathrm{i}} \quad=1$ if $\mathrm{i}$ has automatically qualified to enter tournaments (exempt);

$\mathrm{EX}_{\mathrm{i}}=0$ if $\mathrm{i}$ has not automatically qualified (non-exempt)

$\mathrm{AO}_{j}=1$ if the Australian Open; $\mathrm{AO}_{j}=0$ if otherwise

$\mathrm{RQ}_{\mathrm{ij}}=\mathrm{PA}_{\mathrm{i}} / \mathrm{TA}_{\mathrm{ij}}$

$\mathrm{PA}_{\mathrm{i}} \quad=\mathrm{i}$ 's scoring average for the Tour

$\mathrm{TA}_{i j}=$ mean value of $\mathrm{PA}_{\mathrm{i}}$ for all $\mathrm{i}$ who finished tournament $\mathrm{j}$

$\mathrm{NT}_{\mathrm{j}}=$ number of top 20 money winners who finished tournament $\mathrm{j}$

$\mathrm{PC}_{\mathrm{j}} \quad=$ par for the tournament course $\mathrm{j}$

$\mathrm{CL}_{\mathrm{j}} \quad=$ course length for the tournament course $\mathrm{j}$

$\mathrm{PZ}_{\mathrm{j}} \quad=$ total tournament prize money (in 000 Australian dollars)

$\varepsilon_{i j} \quad=$ disturbance term

Although limited to some extent by the scope of the available data, the present study includes many of the tournament-specific variables introduced in previous research. These are factors that exist in tournaments which can be expected to affect individual performance for any given incentive structure. Par for the course $\left(\mathrm{PC}_{\mathrm{j}}\right)$ and its total length $\left(\mathrm{CL}_{\mathrm{j}}\right)$, for example, give an indication of the degree of difficulty of each tournament course. Additional information available to Ehrenberg and Bognanno, namely, a PGA evaluation of the playing difficulty of a course and the number of days during which weather conditions could have impaired player performance, was not available for the Australasian Tour $^{3}$ A dummy variable $\left(\mathrm{A}_{\mathrm{j}}\right)$ is included for the Australian Open as the major tournament in the Tour; winning the Open has implications that go well beyond the level of prize money to include future sponsorship and advertising income. In addition, and in order to examine the possibility that the relationship between financial incentive and performance will vary between different groups of players, the model separates exempt from non-exempt players $\left(\mathrm{EX}_{\mathrm{i}}\right)$ and considers the specific performance of the top twenty money winners on the 1991 Australasian Tour who finished in the tournament $\left(\mathrm{NT}_{\mathrm{j}}\right)$.

There are, however, differences in the approach adopted in this study and that followed by Ehrenberg and Bognanno. For example, the relationship between total prize money and individual performance on the Australasian Tour focuses on the final score after four rounds

Australasian Tour differs little between exempt players and those non-exempt players anxious to achieve exemption status.

3 The Official PGA Tour Guide 1991 does offer information on weather conditions. This, however, is not detailed enough to gauge with any degree of certainty the likely impact on tournament performance. 
$\left(\mathrm{FS}_{\mathrm{ij}}\right)$. It was not possible to test the "final-round score equation" specified in Ehrenberg and Bognanno ${ }^{4}$ for two reasons. One, their particular model has a simultaneous equation nature which is estimated by using instrumental variable techniques; this was not possible in the present study due to the non-linear nature of the approach adopted. Two, the finalround score approach could generate negative (variable) values which are impossible to use with the Box-Cox procedures. Another difference is that a player's scoring average for the Australasian Tour $\left(\mathrm{PA}_{\mathrm{i}}\right)$ and the mean value of $\mathrm{PA}_{\mathrm{i}}$ for all $\mathrm{i}$ who finished tournament $\mathrm{j}$ $\left(\mathrm{TA}_{i j}\right)$ are combined as $\mathrm{RQ}_{\mathrm{ij}}=\mathrm{PA}_{i} / \mathrm{TA}_{\mathrm{i}}$. Ehrenberg and Bognanno use these as separate variables in their estimated equations. This raises a number of concerns. One, because $\mathrm{PA}_{i}$ and $\mathrm{TA}_{i j}$ are absolute measures (whereas $\mathrm{RQ}_{i j}$ is a relative measure), including them separately does not properly represent the relative quality of the $i^{\text {th }}$ player. A relative measure tests that the above average player's chances of winning are good if he performs up to his potential, and that a below average player needs to perform better in order to win. Two, the simple correlation coefficient between PA and TA is high which might indicate serious multicollinearity. Entering them separately did show the estimated coefficients to be statistically insignificant.

It is clear that equation (1) cannot be estimated unless one makes explicit assumptions about the functional relationship between the explanatory variables and $\mathrm{FS}_{i j}$. Ehrenberg and Bognanno make a priori assumptions about the functional form without any statistical tests. Here, for the first time, the appropriate form will be explicitly tested. For this purpose, the Box-Cox (1964) general transformation function will be used and, hence, the specification given in the Appendix will be estimated.

\section{The results and implications}

The summary statistics for each variable under consideration are reported in Table III. Estimates of the non-linear model specified in the appendix and its restricted versions (the linear and log-linear models) for the entire sample $(n=820)$, the exempt players $(n=364)$ and the non-exempt players $(n=456)$ are reported in Table IV.

It can be seen from the nine equations presented that the conclusions that can be drawn from the three different samples used are the same and, therefore, the qualitative implications of different equations are identical. This robustness is also confirmed by the restrictions on the functional form. Although, using appropriate likelihood ratio tests, the estimated equations obtained conclusively show that the linear model $(\lambda=1)$ is not appropriate, it still yields qualitative results which are consistent with the non-restricted specification and the more appropriate log-linear specification.

4 The 'final-round score equation' tests whether the financial incentive of greater marginal returns from improving one's ranking in the last round leads to a lower final-round score. This is discussed in Ehrenberg and Bognanno (1990a, 1318-1321 and 1990 b, 81-85). To estimate how total prize money influences performance in the first two rounds of a tournament, Ehrenberg and Bognanno (1990a, 1315-1318) also include a 'score after second-round equation' for the 1984 United States tournaments. The results show that prize money does not influence performance in the early stages of a tournament. The same approach was actually adopted for the Australasian Tour and the results are not statistically significant and are not reported. 
TABLE IV

Estimated Equations for the 1991 PGA Australasian Tour

$\alpha$

$\alpha_{2} \quad \beta_{1}$

$\beta_{1} \quad \beta_{2}-\beta_{3}$

$\beta_{4}$

$\rho$

$\lambda$

$\mathrm{R}^{2}$

LLF

$\chi^{2}$

ENTIRE SAMPLE $(\mathbf{n}=\mathbf{8 2 0})$ :

(1)

$0.324 \quad-0.003$

$(-1.67)^{*} \quad(-14.36) \quad(18.06)$

(2)

$-0.224 \quad-0.006$

$(-0.78)^{*} \quad(-4.38)$

(18.06)

(15.76)

(16.11)

1.229
$(17.53)$

$\begin{array}{rr}-0.060 & -0.024 \\ (-1.38)^{*} & (-14.09)\end{array}$

$-0.14$

0.466

$-2491.4$

(18.21)

0.662
$(15.76)$

0.029

(15.87)

1.484

$(-1.38)^{*} \quad(-14.09)$

$-0.14$

0.466

$-2491.4$

$\begin{array}{ll}180.920 & 0.792\end{array}$

(17.47)

$-0.043 \quad-0.023$

0

0.466

$-2491.9$

$1.0^{+}$

$(-9.24) \quad(-4.108)$

$(17.06) \quad(14.44)$

(11.678)

5.389

$-0.003$

$(-14.36)$

(15.817)

$(-2.29)$

-0.012
$(-13.53)$

1

0.430

$-2518.9$

54.0

EXEMPT PLAYERS $(\mathbf{n}=364)$ :

$\begin{array}{lcc}\text { (1) } & -1.922 & 0.157 \\ & (-1.73)^{*} & (9.90) \\ \text { (2) } & -0.210 & 0.473 \\ & (-0.39)^{*} & (9.82) \\ \text { (3) } & -249.790 & 13.231 \\ & (-4.75) & (9.56)\end{array}$

1.895

(6.38)

0.055

(7.51)

0.571

(6.80)

0.261

$\begin{array}{lll}1.947 & -0.025 & 0.018\end{array}$

$\begin{array}{ccc}(10.74) & (-1.13)^{*} & (-7.33) \\ 1.461 & -0.369 & -(0.020\end{array}$

(7.64)

1.461

$\begin{array}{ll}-0.369 & -0.020\end{array}$

$\begin{array}{lll}(10.73) & (-0.87)^{*} \quad(-7.17)\end{array}$

0.21

$0.354 \quad-1121.8$

158.950

0.694

5.547

(6.49)

(6.27)

5.547
$(10.44)$

$-0.004$

$(-1.78)^{*}$

$-0.010$

$(-7.20)$

0

$0.353 \quad-1122.1$

$0.6^{+}$

NON-EXEMPT PLAYERS $(\mathrm{n}=456)$ :

(1)

$\begin{array}{lr}0.803 & 0.007 \\ (3.48) & (14.63)\end{array}$

(2) $\quad-0.096$

$(-0.28)^{*}$

(14.63)

0.097

$\begin{array}{ll}0.097 & 0.008\end{array}$

0.911

$-0.112 \quad-0.026$

$(-0.95)^{*} \quad(-11.51)$
$-(0.038$

$-0.35$

0.533

$0.699 \quad 0.030$

$(14.44) \quad(13.67)$

1.446

$-0.038$

(12.36)

$(-0.95)^{*}$

$-0.025$

(14.93)

$188.270 \quad 0.833$

$(-7.12)$

13.641
$(13.53)$

$(9.25)$

5.000
$(1039)$

\begin{tabular}{rr}
-0.002 & -0.013 \\
$(-0.93)^{*}$ & $(-10.95)$ \\
\hline
\end{tabular}

$(-12.18)$

$-0.013$

0

0.528

$-1361.51$

5.0 (12.76)

1

$0.470 \quad-1388.4$

53.8

Notes: Asymtotic t-statistics are given in parentheses $(*$ denotes that the estimated coefficient is not statistically significantly different from zero at the 0.05 test level). The $\chi^{2}$ values reported are the appropriate likelihood ratio used to test the hypothesis $\mathrm{H}_{\mathrm{O}}: \lambda=0$ or $\lambda=1$ against $\mathrm{H}_{1}: \lambda \neq 0$ or $\lambda \neq 1$ ( ${ }^{+}$denotes that the estimated restricted model is not statistically significantly different from the unrestricted one at the 0.05 test level) 
All estimated coefficients, except $\beta_{4}$ (namely, the course length), are statistically significant at the conventional test levels with correct signs. This clearly suggests that all the variables but one listed in Table IV play a statistically significant role in explaining the final score $\left(\mathrm{FS}_{\mathrm{v}}\right)$. Given the major thrust of the present study, it is important to note that the prize money coefficient, $\rho$, has the correct sign (negative) and is highly significant in all nine estimated equations. This patently confirms that total prize money does offer an incentive to improve the level of performance even though financial incentives, on the whole, are appreciably less than PGA tournaments in the United States and Europe.

TABLE III

Descriptive Statistics for the Entire Sample $(n=820)$

\begin{tabular}{lllll}
\hline Variable & Mean & SD & Min & Max \\
\hline FS $_{i j}$ & 290.07 & 6.92 & 271.00 & 309.00 \\
$\mathrm{EX}_{i}$ & 0.45 & 0.50 & 0.00 & 1.00 \\
$\mathrm{AOj}$ & 0.078 & 0.268 & 0.00 & 1.00 \\
$\mathrm{RQ}_{i j}$ & 0.99 & 0.02 & 0.94 & 1.07 \\
$\mathrm{NT}_{j}$ & 10.43 & 4.72 & 2.00 & 18.00 \\
$\mathrm{PC}_{j}$ & 71.92 & 0.83 & 70.00 & 73.00 \\
$\mathrm{CL}_{j}$ & 6251.40 & 239.20 & 5771.00 & 6682.00 \\
$\mathrm{PZ}_{j}$ & 475.81 & 335.28 & 150.00 & 1200.00 \\
\hline
\end{tabular}

Note: for the definition of variables see text.

Some results deserve additional comment. The coefficient $\alpha_{2}$, for the Australian Open, is significant but has a positive sign. This runs counter to Ehrenberg and Bognanno (1990a: 1314 and 1990b: 80). Their results show that scores are lower for major tournaments in the United States and Europe which offer a range of financial inducements in excess of total prize money. Although "rewards" for the Australian Open are similarly attractive, higher scores are explained by the course being prepared deliberately as a much tougher test for golfers than other tournaments on the Australasian Tour. ${ }^{5}$ The coefficient $\beta_{4}$, for the length of a course, suggests it has a negative but statistically insignificant effect on the tournament score. Again, the Ehrenberg-Bognanno results (1990a: 1314 and 1990b: 80) show the opposite: increasing the length of a course increases the final score statistically significantly. This suggests that course length adversely affects United States and European players, but

s Most tournament courses are prepared consistently to standards set by the PGA. Conditions relating to the Australian Open (and the NZ Shell Open for that matter) are determined by a 'local committee' which makes the course tougher than standards normally imposed by the PGA. 
has no significant effect on Australasian players (and, if anything, helps their performance). One reason for this is that courses, on average, are shorter in the southern hemisphere than most of those used for tournaments on the United States and European circuits. Relatively longer courses used on the Australasian Tour are less likely to adversely affect performance than long courses in the northern hemisphere. Furthermore, many short courses are acknowledged as a severe test of a player's ability and, therefore, longer courses on the Australasian Tour are a little easier than shorter courses. The impact of other variables on performance - those relating to the relative quality of players $\left(\beta_{1}\right)$, the performance of the top twenty money winners $\left(\beta_{2}\right)$ and course difficulty $\left(\beta_{3}\right)$ - are as expected and confirm Ehrenberg and Bognanno's results. However, it is worth noting that on the Australasian Tour, unlike United States and European tournaments, the results seem to suggest that the incentive to improve performance does not differ greatly between exempt and non-exempt players.

In contrast to recent interest in tournament models, the more general idea that worker productivity is influenced by the size of the wage goes back many years. For a number of reasons, particularly in situations where the potential for long-term attachment between workers and firms exists, it may prove profitable for employers to pay above the going market rate. One explanation for this is that higher wages could lead to reduced labour turnover and a consequent saving in hiring and training costs. Furthermore, higher wages will attract a higher quality labour force. Again, the higher earnings (compared to lower potential earnings elsewhere) generate an incentive not to shirk and run the risk of discharge. In this case, the firm benefits further by a reduction in supervising and monitoring costs. In addition, it has been argued that the "gift" of higher wages by an employer encourages a reciprocal "gift" of increased effort by employees (Ehrenberg and Smith, 1991: 423). The present study confirms this and points to the growing interest in tournament-type incentive structures as one explanation for the economy of higher wages.

\section{Conclusion}

Central to the theory of tournaments is the hypothesis that, given the total of prize money and the distribution of this prize money, financial rewards offer an incentive to provide improved levels of performance. Applied particularly to golf tournaments, the theory implies that increases in prize money will lead to lower scores. This study based on the Australasian Tour of 1991 clearly confirms this. All but one of the variables listed in Table IV play a significant role in explaining the final score and the prize money coefficient is highly significant and has the correct sign.

The reliable pool of data from sporting competitions does offer a means to test economic hypotheses (see Goff and Tollison, 1990). Of particular interest in the present study is the extent to which it supports the basic proposition underlying the efficiency - wage model that the structure of compensation affects productivity. It does show that the Australasian Tour encourages desired effort responses; the evidence does confirm the existence of a positive wage-productivity nexus. 


\section{Appendix}

The estimated equations which are examined in the text were obtained from the following non-linear Box-Cox specification:

$$
\begin{aligned}
& f\left(\mathrm{FS}_{i j}\right)=\alpha_{0}+\alpha_{1} \mathrm{EX}_{\mathrm{i}}+\alpha_{2} \mathrm{AO}_{j}+\beta_{1} f\left(\mathrm{RQ}_{i j}\right)+\beta_{2} f\left(\mathrm{NT}_{\mathrm{j}}\right. \\
& +\beta_{3} f\left(\mathrm{PC}_{\mathrm{j}}\right)+\beta_{4} f\left(\mathrm{CL}_{\mathrm{j}}\right)+\rho f\left(\mathrm{PZ}_{\mathrm{j}}\right)+\varepsilon_{\mathrm{ij}} \\
& \text { where } \quad f(\mathrm{x})=\left(\mathrm{x}^{\lambda}-1\right) / \lambda
\end{aligned}
$$

Equation (1A) gives the Ehrenberg and Bognanno model which is linear and yields the loglinear constant elasticity model when $\lambda=0$ (see, for example, Bairam, 1991 a and b; Bairam and Howells, 1989). A problem with the above specification, however, is that it assumes that the transformation simultaneously yields the appropriate functional form and disturbances $\left(\varepsilon_{i j}\right)$ that are approximately normally distributed and homoscedastic. Zarembka (1974) showed that when $\varepsilon_{i j}$ are heteroscedastic the estimated $\lambda$ will be biased in the direction required for the transformed dependent variable to be nearly homoscedastic. To overcome this problem, equation (1A) was estimated by the appropriate maximum likelihood method available in the Shazam computer programme (see White, 1974).

\section{References}

Akerlof, G.A. (1984), Gift Exchange and Efficiency-Wage Theory: Four View, American Economic Review, 74: 79-83.

Akerlof, G.A. and Yellen, J.L. (eds.) (1986), Efficiency Wage Models of the Labor Market, Cambridge, Cambridge University Press.

Bairam, E.I. (1991a), Elasticity of Substitution, Technical Progress and Returns to Scale in Branches of Soviet Economy: A New CES Production Approach, Journal of Applied Econometrics, 6: 91-96.

Bairam, E.I. (1991b), Functional Form and New Production Functions: Some Comments and a New VES Function, Applied Economics, 23: 1247-1249.

Bairam, E.I. and Howells, J.M. (1989), Strike Incidence in New Zealand: A New Econometric Approach, Australian Economic Papers, 28: 93-102.

Carmichael, H.L. (1983), The Agent - Agents Problem: Payment by Relative Output, Journal of Labor Economics, 1: 50-65.

Ehrenberg, R.G. and Bognanno, M.L. (1990a), Do Tournaments Have Incentive Effects?, Journal of Political Economy, 98: 1307-1324. 
Ehrenberg, R.G. and Bognanno, M.L. (1990b), The Incentive Effects of Tournaments Revisited: Evidence for the European PGA Tour, Industrial and Labor Relations Review, 43: $74-88$.

Ehrenberg, R.G. and Smith, R.S. (1991), Modern Labor Economics: Theory and Public Policy, New York, Harper Collins.

Goff, B.L. and Tollison, R.D. (1990), Sports as Economics. In Goff, B.L. and Tollison, R.D. (ed.), Sportometrics, College Station, Texas A \& M University Press.

Green, J.R. and Stokey, N.L. (1983), A Comparison of Tournaments and Contracts, Journal of Political Economy, 91: 349-365.

Lazear, E.P. and Rosen, S. (1981), Rank-Order Tournaments as Optimum Labor Contracts, Journal of Political Economy, 89: 841-864.

Malcomson, J.M. (1984), Work Incentives, Hierarchy, and Internal Labor Markets, Journal of Political Economy, 92: 486-507.

McLaughlin, K.J. (1988), Aspects of Tournament Models: A Survey. In Ehrenberg, R.G. (ed.), Research in Labor Economics, Greenwich, Conn., JAI.

Nalebuff, B.J. and Stigiltz, J.E. (1984), Prizes and Incentives: Towards a General Theory of Compensation and Competition, Bell Journal of Economics, 15: 21-43.

Official PGA Tour Guide 1991 (1992), Silverwater, N.S.W., Link Printing.

O'Keefe, M., Viscusi, W.K. and Zeckhauser, R.J. (1984), Economic Contests: Comparative Reward Schemes, Journal of Labor Economics, 2: 27-56.

Rosen, S. (1986), Prizes and Incentives in Elimination Tournaments, American Economic Review, 76: 701-716.

Stiglitz, J.E. (1987), The Causes and Consequences of the Dependence of Quality on Price, Journal of Economic Literature, 25: 1-48.

White, K.J. (1978), A General Computer Program for Econometric Methods-Shazam, Econometrica, 46: 139-140.

Yellen, J.L. (1984), Efficiency Wage Models of Unemployment, American Economic Review, 74: 200-205.

Zarembka, P. (1974), Transformation of Variables in Economics, in Zarembka, P. (ed.), Frontiers in Econometrics, New York, Academic Press. 